\title{
Association of paratuberculosis sero-status with milk production and somatic cell counts across 5 lactations, using multilevel mixed models, in dairy cows
}

\author{
E. G. Martins, ${ }^{*} \dagger \ddagger^{1}$ P. Oliveira, ${ }^{*} \dagger$ B. M. Oliveira, $\S$ D. Mendonça, ${ }^{*} \dagger$ and J. Niza-Ribeiro ${ }^{*} \dagger$ \\ *Instituto de Ciências Biomédicas Abel Salazar, Universidade do Porto, 4050 Porto, Portugal \\ †EPIUnit, Instituto de Saúde Pública da Universidade do Porto, 4050 Porto, Portugal \\ ‡Department of Veterinary Medicine, Escola Universitária Vasco da Gama, 3020 Coimbra, Portugal \\ §Centro de Investigação em Tecnologias e Serviços de Saúde (CINTESIS), Center for Health Technology and Services Research, \\ Faculty of Medicine, University of Porto, 4050 Porto, Portugal
}

\begin{abstract}
The aim of this work was to investigate associations between individual cow Mycobacterium avium ssp. paratuberculosis (MAP) seropositivity, 305-d corrected milk production, and somatic cell count during 5 lactations lifespan in Portuguese dairy herds using multilevel mixed models. We used MAP serum ELISA (Idexx MAP Ac, Idexx Laboratories Inc., Westbrook, $\mathrm{ME})$ results $(\mathrm{n}=23,960)$ from all the 20,221 adult cows present in 329 farms and corresponding 47,586 lactation records from the National Dairy Improvement Association. Cows and farms were classified as positive or negative. Multilevel mixed models were used to investigate the association of cow MAP status with variation in milk production and somatic cell count. Cow MAP status, farm status, and lactation number were considered as independent variables. A quadratic function of lactation number was used to mimic the effect of lactation order on milk production. The models considered 3 levels: measurement occasion (level 1) within cow (level 2) and cow within farm (level 3). Four final models were produced, including all herds and cows, to address the effect of farm status (models 1 and 2) or the effect of cow status (models 3 and 4) on the outcome variables. Our results show that MAP status affects milk production. Losses are detectable from third lactation onward. During the first 5 lactations, positive cows accumulated an average loss of $1,284.8$ $\mathrm{kg}$ of milk when compared with the negative cows. We also observed that somatic cell counts were higher in positive cows and a positive interaction occurs between cow status and lactation number, suggesting a positive association between MAP infection and increased so-
\end{abstract}

Received August 26, 2017.

Accepted April 13, 2018.

${ }^{1}$ Corresponding author: ebete.martins@sapo.pt matic cell counts. Our results are in line with previous studies, suggesting a possible positive relation between cow milk production and susceptibility to MAP infection.

Key words: paratuberculosis, milk production, somatic cell count, multilevel mixed model

\section{INTRODUCTION}

Paratuberculosis, or Johne's disease, is a chronic granulomatous enteric disease affecting both ruminant and nonruminant animals caused by Mycobacterium avium ssp. paratuberculosis (MAP). No fully effective tools or strategies exist to prevent new infections or disease progression. Effects of MAP on animal welfare are relevant and the effect on dairy operations has been linked to impaired udder health, milk production (McAloon et al., 2016; Pritchard et al., 2016; Smith et al., 2016), and reproductive performance (Donat et al., 2014; Mato et al., 2015; Pritchard et al., 2017).

A strong association has been documented between MAP and Crohn's disease (Waddell et al., 2015), but important knowledge gaps to establish the causal path still exist (More et al., 2017). Genetic mimicry between protein epitopes of MAP and human proteins have been associated with autoimmune disorders (Davis, 2015; Sechi and Dow, 2015; Singh et al., 2016).

Diagnosis of MAP infection and measurement of infection effects are difficult because of the long incubation period, lack of diagnostic tests that accurately determine present and future status of the animal, disease dynamics at animal and farm level, and case definition of the positive animal. These factors contribute to the considerable number of studies available in the literature reporting varying effect estimates (McAloon et al., 2016) and prevalence (Nielsen and Toft, 2009). Control programs are mostly based on regular testing of adult animals' blood or milk samples with an ELISA test. Serum ELISA measures humoral response to the 
presence of MAP. During early stages of infection, a cellular immune response is produced, whereas antibody production develops in later stages of infection, which translates to different test accuracy in different stages of infection (Stabel et al., 2014; Laurin et al., 2015, 2017). Although serum ELISA specificity is considered to be greater than $97 \%$, sensitivity can vary from 15 to $75 \%$ depending on the stage of the disease (Timms et al., 2011; Mitchell et al., 2015) and also on milk yield, lactation, herd prevalence, DIM, milk protein, and SCC (Eisenberg et al., 2015).

The disease is disseminated worldwide, and no countries have published enough information to claim freedom from MAP infection; true prevalence among cattle appears to be approximately $20 \%$, and at least 3 to $5 \%$ in several countries, whereas between-herd prevalence was guesstimated to be $>50 \%$ (Nielsen et al., 2009). Correia-Gomes et al. (2010) reported a proportion of $45.9 \%$ positive farms and $2.3 \%$ apparent prevalence at cow level in northern Portugal. No official MAP control programs exist in Portugal; current control strategies are based on voluntary control programs. The national prevalence or production effects have not been assessed thus far. The purpose of the present study was to analyze the effect of individual cow's seropositivity to MAP on 305-d corrected milk production and SCC based on data from the first 5 lactations of each cow in Portuguese dairy herds, using multilevel mixed model (MLM) given the hierarchical nature of the data.

\section{MATERIALS AND METHODS}

\section{Data Collection}

This study combines a cross-sectional structure with a longitudinal component. First, all cows $\geq 30$ mo of age, present at the farms, were blood sampled to determine their MAP serological status. In the longitudinal component the milk production and SCC from first up to fifth consecutive lactations of those same cows were, retrospectively, recorded and used to assess the associations between MAP seropositivity, milk production, and SCC. For some cows, additional blood ELISA results were available and were used when establishing MAP status.

Data set 1 had 23,960 MAP ELISA blood serum results from 20,221 cows from 329 dairy farms enrolled in a Johne's disease voluntary control program in Portugal, designated BOVICONTROL run by SEGALAB (Laboratório de Sanidade Animal e Segurança Alimentar S.A., Argivai, Portugal) animal health laboratories, which is a dairy farmer-sourced company operating in Portugal. All cows present at those farms were tested if they were $\geq 30$ mo. The ELISA tests were performed by
SEGALAB animal laboratory (http://www.segalab.pt/ web/guest/home), which operates under an ISO 17025 quality system (http://www.ipac.pt/pesquisa/ficha_lae .asp?id=L0295). A commercial kit (Idexx MAP Ab, Idexx Laboratories Inc., Westbrook, ME) was used according to the manufacturer's instructions (https:// www.idexx.com/en/livestock/livestock-tests/ruminant -tests/idexx-paratuberculosis-screening-ab-test/). Idexx MAP ab is a monophasic indirect ELISA with the wells coated with a protoplasmic extract of MAP; before the assay, the sera samples were incubated with an extract of Mycobacterium phlei to neutralize any possible cross-reactions with atypical mycobacteria. The individual test results were assigned as follows: sample-to-positive ratio $\leq 45 \%$ was negative, $\geq 55 \%$ was positive, and dubious or suspect for results falling in between. Data set 2 was extracted from the National Dairy Improvement Association (NDIA) database (https://www.bovinfor.pt/Bovinfor/bovinfor.php) and had 305-d corrected lactation records from cows present in data set 1 , corresponding to 47,586 cows. Lactations were included whether they were at least $305 \mathrm{~d}$, or corrected according to Vasconcelos et al. (2004) if they were 210 and less than $305 \mathrm{~d}$; this data set holds records from August 11, 1997, to March 19, 2013. Data set 3 was obtained from the Portuguese Veterinary Authority (DGAV, Lisbon, Portugal) and included the birth date, farm of birth, and between-farm movements for each cow. Data set 4 was created by the authors and gathers and expands the data from the previous data sets in a Microsoft Access 2013 (Microsoft Corp., Redmond, WA) database. The official unique ear tag identification (ID) number was chosen as the primary key for each cow. The final database contained cow ID number, birth farm and birth date (from data set 3), ELISA results (from data set 1), calving date, lactation number, lactation-weighted arithmetic average SCC within the lactation, 305-d corrected milk yield, and farm in which the lactation occurred (data set 2). Calculated fields in each record included daily average 305-d corrected milk production (D305MP), which was calculated by dividing 305-d corrected milk yield by $305 \mathrm{~d}$, and natural $\log$ of the lactation-weighted arithmetic average SCC (lnSCC). The D305MP was used instead of 305-d corrected milk yield to avoid mathematical constrains in the convergence of the estimates of high numbers. Reports for statistical analysis were generated with the queries to the database. From the 20,221 cows ELISA tested, only those registered in NDIA $(15,196)$ were used. Cow lactation and farm observations are presented in Table 1. Exploratory and descriptive analysis were performed using Excel 2013 (Microsoft Corp. Redmond, WA) and IBM SPSS Statistics, version 23 (IBM Corp., Armonk, NY). 
Table 1. Total number of farms and observed lactations per farm $\mathrm{MAP}^{1}$ status

\begin{tabular}{|c|c|c|c|c|c|}
\hline Farm MAP status $^{2}$ & $\begin{array}{l}\text { Total number } \\
(\%) \text { of farms }\end{array}$ & $\begin{array}{l}\text { Number (\%) of } \\
\text { observed cows }\end{array}$ & $\begin{array}{c}\text { Number }(\%) \\
\text { of observed } \\
\text { lactations }\end{array}$ & $\begin{array}{l}\text { Number }(\%) \text { of } \\
\text { observed lactations } \\
\text { per MAP status }\end{array}$ & $\begin{array}{l}\text { Number }(\%) \text { of } \\
\text { observed cows } \\
\text { per cow status }\end{array}$ \\
\hline SNEG & $\begin{array}{l}48 \\
(14.56)\end{array}$ & $\begin{array}{l}2,677 \\
(17.17)\end{array}$ & $\begin{array}{l}7,242 \\
\quad(18.07)\end{array}$ & $\begin{array}{r}\text { NEG: } 7,242 \\
(18.10)\end{array}$ & $\begin{aligned} \text { NEG: } & 2,677 \\
& (17.17)\end{aligned}$ \\
\hline NEG & $\begin{array}{l}125 \\
(38.00)\end{array}$ & $\begin{array}{l}516 \\
(3.31)\end{array}$ & $\begin{array}{l}890 \\
(2.22)\end{array}$ & NEG: 890 & NEG: 516 \\
\hline NNEG & $\begin{array}{l}60 \\
(18.24)\end{array}$ & $\begin{array}{l}2,588 \\
\quad(16.60)\end{array}$ & $\begin{array}{l}7,027 \\
\quad(17.54)\end{array}$ & $\begin{aligned} \text { NEG: } 6,816 \\
(17.00) \\
\text { DUB: } 52 \\
(0.10) \\
\text { POS: } 159 \\
(0.40)\end{aligned}$ & $\begin{aligned} & \text { NEG: } 2,515 \\
&(16.13) \\
& \text { DUB: } 21 \\
&(0.13) \\
& \text { POS: } 52 \\
&(0.33)\end{aligned}$ \\
\hline POS & $\begin{array}{l}96 \\
(29.18)\end{array}$ & $\begin{array}{l}9,811 \\
\quad(62.92)\end{array}$ & $\begin{array}{l}24,906 \\
\quad(62.16)\end{array}$ & $\begin{aligned} \text { NEG: } 22,995 \\
(57.40) \\
\text { DUB: } 198 \\
(0.50) \\
\text { POS: } 1,713 \\
(4.27)\end{aligned}$ & $\begin{aligned} \text { NEG: } 9,092 \\
(58.31) \\
\text { DUB: } 68 \\
(0.44) \\
\text { POS: } 651 \\
(4.18)\end{aligned}$ \\
\hline
\end{tabular}

${ }^{1} \mathrm{MAP}=$ Mycobacterium avium $\mathrm{ssp}$. paratuberculosis.

${ }^{2}$ Farm MAP status: SNEG = strong negative; NEG = negative; NNEG = non-negative; POS = positive.

${ }^{3}$ Cow and lactation MAP status: NEG = negative; DUB = dubious; POS = positive.

${ }^{4}$ There were 390 cows that moved 396 times between farms during their productive life. Total number of cows in the study is 15,196 ; total number of cow/farm observations is 15,592 .

\section{Definition of MAP Status}

Cows' MAP status (CS) was assigned as positive (POS) when the cow had at least 1 positive ELISA test result, as dubious (DUB) when at least 1 cow's test result was dubious and none was positive, and as negative (NEG) when all test results were negative. From 20,221 cows available in our database, 6 had 4 test results, 535 had 3 tests, 2,576 had 2 test results, and the remaining 17,104 had only 1 test result. All lactations were assigned the same CS; farm MAP Status (FS) was assigned based on the ELISA results of all the 20,221 cows from data set 1 . Farms were classified as POS, non-negative (NNEG), NEG, and strong negative (SNEG). A farm was classified as POS if all the cows aged 30 mo or older were tested and at least 2 cows were POS; NNEG if all cows were tested and at least 1 cow was DUB or no more than 1 cow was POS; NEG if all cows were tested and NEG, but less than 60 ELISA results were available for the farm; and SNEG if the farm had at least 60 ELISA results and had at least 20 cows equal or over 30 mo old.

\section{Data for Multivariable MLM}

To assess the effect of MAP status on D305MP and on $\operatorname{lnSCC}$, lactations with nonvalid observations, lactations on farms other than the original farm, or cows not present in NDIA were excluded; moreover, lactations from farms with fewer than 20 cows or lactations higher than the fifth were also excluded. This was done to prevent the occurrence of data classes with small number of observations that would preclude the validity of the statistical models results. Three-hundred ninety cows moved 396 times between farms during their productive life. A total of 191 farms, including 14,829 cows and their respective 36,219 lactations, were retained from data set 4 for MLM analysis (Table 2).

Farm MAP status was rearranged for this analysis and considered as POS or NEG (aggregating SNEG, NEG, and NNEG). Cows were classified as POS or NEG; DUB cows $(0.62 \%$ of the total observed lactations) were treated as NEG.

\section{Statistical Analysis}

Lactation-weighted arithmetic average SCC within the lactation, which presented a right skewed distribution, was log transformed so that its distribution became approximately normal. Lactation number $(\mathbf{L})$ minus 1, was used in the models so that the interception values could be easily interpreted (mean value of the first lactation for NEG cow or farm status coded as zero).

Collected data had a natural hierarchical structure and was analyzed using multilevel statistical models considering the measurement occasion (first level) nested within cows (second level) and cows nested in farms (third level). It should be stressed that our data have a longitudinal component that is properly addressed by 
the MLM models, which takes into account the different numbers of observations by cow, given that some cows may have observations for just 1 lactation and for others, 2, 3, or up to 5 lactations.

Several multivariable MLM, having as dependent variable D305MP or $\operatorname{lnSCC}$ and as explanatory variables L, CS, or FS and cross-level interactions, were fitted. All models had at least 3 variance components: a residual variance at level 1 and random intercept variances at level 2 and level 3, allowing for the 3-level data structure. To decide which variables and random terms should be included in the final models, the significance of the fixed effects was assessed by Wald tests, whereas random effects were evaluated using likelihood ratio tests. Models were fitted using maximum likelihood estimation and an unstructured random-effects variance/covariance matrix. The final models included only the significant interaction and random effects. The significance level was set at 0.05 .

Preliminary analyses revealed that the 3-level models should include a linear and a quadratic effect of lactation number, and a random linear lactation slope at level 2 and 3. Models were developed with SuperMix 2.1 (Scientific Software International Inc., Lincolnwood, IL) and Stata 11.2 (StataCorp LLC, College Station, TX) statistical packages. Stata 11.2 was used to graphically display the model results.

Two model structures were used and the corresponding equations are presented in the Appendix. In the models in which the effect of CS was to be investigated (A model), the interaction between CS and L was considered to be included. When investigating the effect of FS (B model), the interaction between FS and L was analyzed.

Based on the general model described, several models were produced and 4 final models were retained. Models used all data (farms, cows, and lactations) to assess the effects, respectively, of FS and CS on D305MP (models
1 and 3 ) and on $\operatorname{lnSCC}$ (models 2 and 4). Similar models (results in Supplemental Table S1; https://doi.org/ 10.3168/jds.2017-13746) were restricted to NEG cows from all herds, assessing the effect of FS (models 5 and 6 ), or restricted to the data of POS farms, assessing the effect of CS (models 7 and 8).

To estimate the average losses of milk production of an infected cow over the first 5 consecutive lactations, the parameters estimates of model 3 were used. The production estimates for the average POS cow and the average NEG cow were performed for each lactation. Differences of production for each lactation were then calculated and cumulative 5-lactation differences were obtained by summing the 5 differences.

\section{RESULTS}

\section{Descriptive Results}

Number of farms, cows, and lactations categorized by MAP status are shown in Table 1 . There were 15,196 cows in 329 farms. Of these, 390 moved between farms 396 times. Consequently, these cows were observed in more than 1 farm, resulting in 15,592 cow-farm observations. The proportion of positive farms, positive cows, and positive lactations was $29.2,4.5$, and $4.7 \%$, respectively. The median number of lactations per farm was 77 (first quartile 2, third quartile 161). Relative frequencies of first 3 lactations were $35.9,28.4$, and $18.0 \%$, respectively. Only $18.1 \%$ of observed lactations belonged to cows in SNEG farms. Positive farms harbored $57.4 \%$ of the NEG lactations.

The average 305-d corrected milk production per cow was $9,427 \mathrm{~kg}(\mathrm{SD}=1,910)$. An increase in the average milk production was observed from first to third lactation (8,786 to $9,974, \mathrm{SD}=1,544$ and 2,019 , respectively), followed by a decrease from the fourth lactation onwards. The arithmetic and geometric mean

Table 2. Cross frequencies distribution [no. (\%)] of lactations by cow status and farm status, for multilevel mixed models

\begin{tabular}{|c|c|c|c|c|c|}
\hline \multirow[b]{2}{*}{ Cow status ${ }^{1}$} & \multicolumn{5}{|c|}{ Farm status ${ }^{2}$} \\
\hline & SNEG & NEG & NNEG & POS & Total \\
\hline DUB & 0 & 0 & $\begin{array}{l}48 \\
(0.13)\end{array}$ & $\begin{array}{l}175 \\
\quad(0.48)\end{array}$ & $\begin{array}{l}223 \\
(0.62)\end{array}$ \\
\hline NEG & $\begin{array}{l}6,597 \\
\quad(18.21)\end{array}$ & $\begin{array}{l}278 \\
\quad(0.77)\end{array}$ & $\begin{array}{l}6,037 \\
\quad(16.67)\end{array}$ & $\begin{array}{r}21,393 \\
(59.07)\end{array}$ & $\begin{array}{l}34,305 \\
(94.72)\end{array}$ \\
\hline POS & 0 & 0 & $\begin{array}{l}101 \\
(0.28)\end{array}$ & $\begin{array}{l}1,590 \\
(4.39)\end{array}$ & $\begin{array}{c}1,691 \\
(4.67)\end{array}$ \\
\hline Total & $\begin{array}{l}6,597 \\
\quad(18.21)\end{array}$ & $\begin{array}{l}278 \\
(0.77)\end{array}$ & $\begin{array}{l}6,186 \\
(17.08)\end{array}$ & $\begin{array}{l}23,158 \\
(63.94)\end{array}$ & $\begin{array}{c}36,219 \\
(100)\end{array}$ \\
\hline
\end{tabular}

${ }^{1}$ Cow status: $\mathrm{DUB}=$ dubious; $\mathrm{NEG}=$ negative; $\mathrm{POS}=$ positive.

${ }^{2}$ Farm status: SNEG $=$ strongly negative; NEG = negative; NNEG = non-negative; POS = positive. Bold values were aggregated in negative lactations; SNEG, NEG, and NNEG were aggregated as negative farms. 
of the weighted arithmetic average SCC were $276 \times$ $10^{3}$ and $139 \times 10^{3}$, respectively; median was $122 \times 10^{3}$, first quartile was $60 \times 10^{3}$, and third quartile was 290 $\times 10^{3}$. Less than $60 \%$ of lactations had an SCC below $200 \times 10^{3}$ and $90 \%$ of the observations were below 656 $\times 10^{3}$ cells $/ \mathrm{mL}$.

\section{Multilevel Mixed Models Results}

The results from the 4 final multilevel mixed models and the corresponding number of farms, cows, and lactations are presented in Table 3 and Figure 1. The effect of $\mathrm{L}$ translated by the linear and quadratic terms is significant in all models; these terms account for the curvature associated with D305MP and $\operatorname{lnSCC}$ along the lactations. In particular, it should be noted that D305MP increases from first to third lactation and decreases afterward. The curves obtained from these models are shown in Figure 1.

In models 1 and 2, concerning all cows and farms, D305MP and lnSCC were compared by MAP FS, controlling for L. No difference was observed in D305MP, but a significant interaction of FS with $\mathrm{L}$ was observed in $\operatorname{lnSCC}$, with the increment in $\operatorname{lnSCC}$, as lactation increases, being higher in cows from POS than from NEG farms (Table 3).

In model 3, POS versus NEG cows were compared. A significant interaction between CS and L was found for milk production, which explains the increasing difference in D305MP along lactations, with NEG cows exhibiting a higher production along the complete 5 -lactation period (Table 3). The average cumulative difference in milk production through 5 consecutive lactations was, approximately, $-1,285 \mathrm{~kg}$. However, in their first lactation, POS cows produced on average $0.4 \mathrm{~kg} / \mathrm{d}$ (129.1 kg during a 305-d corrected lactation) more milk than the NEG ones (Table 3). From the second lactation onward, POS cows produce less milk than NEG cows. These differences in production increased from second to fifth lactation and were -0.2 . $-0.8,-1.5$, and $-2.1 \mathrm{~kg}$, respectively.

Regarding lnSCC (model 4), its values were higher in POS cows when compared with NEG cows. Due to the significant interaction between L and CS, the difference increases from first to fifth lactation.

A similar variation pattern was observed in D305MP and $\operatorname{lnSCC}$ when the analysis was restricted to NEG cows (models 5 and 6 ) and only to POS farms, models 7 and 8 (Supplemental Table S1; https://doi.org/10 .3168/jds.2017-13746). Last, the statistical significance of the variance and covariance components reveals the appropriateness of the 3-level model approach (Table $3)$.

\section{DISCUSSION}

Our study provides the first report of MAP effects in Portuguese dairy farms. The proportion of POS farms in our sample was $29.2 \%$; however, the proportion of farms with at least a positive cow was higher, at $47 \%$. The proportion of positive cows was $4.5 \%$. The Portuguese apparent prevalence should not be very different from our estimates (Correia-Gomes et al., 2010). It is important to highlight that, in our sample, only $18.1 \%$ of calvings occurred in potentially MAP-free farms and more than $60 \%$ of calves were born on farms with a MAP risk. This shows that the potential for MAP dissemination among farms and between animals in Portugal is high and the adoption of biosecurity measures toward MAP is relevant.

The assessment of the potential effect of infection in D305MP and lnSCC was carried out using an innovative approach: the lifelong effect of MAP infection across 5 consecutive lactations was assessed using a 3-level structure. Lactation was included in the models, given its effect on the productive life of the cow (Vasconcelos et al., 2004) and as an important risk factor for the MAP infection to become apparent (Smith et al., 2016). By assessing the productive life of each cow over 5 consecutive and dependent lactations, the biology of lifelong pathogenicity and pathogeny of MAP infection (Coelho et al., 2013) were considered. Nielsen et al. (2009) found that production losses due to MAP may become apparent long before seroconversion. This reinforces the importance of following the complete productive life of each cow for a more complete assessment of the production losses. The different types of patterns described for seroconversion or shedding (Nielsen et al., 2009; Smith et al., 2016) that are the result of MAPhost dynamics were not specified in our models. Due to the design of the study, only 1 test was available for the majority of the cows; thus, dynamic evaluation of infection was not possible. However, different seroconversion and shedding patterns are expected to have occurred in our sample of cows even though they were not assessed. By addressing the 5-lactation lifetime period, we evaluated MP and $\operatorname{lnSCC}$ regardless of the potential variations in seroconversion pattern of the POS cow during its life, which was the objective of our work.

In all our models, production increased from first to third lactation and decreased afterward. Lactation number (linear and quadratic) was a highly significant predictor of D305MP and lnSCC in all models (Table 3). The variance/covariance analysis confirms the importance of the selected structure. Each level, measurement occasion, cow, and farm, retain a significant amount of the observed variance in the data. However, variance/ covariance structure was different in the 2 outcomes: a 
DAIRY INDUSTRY TODAY

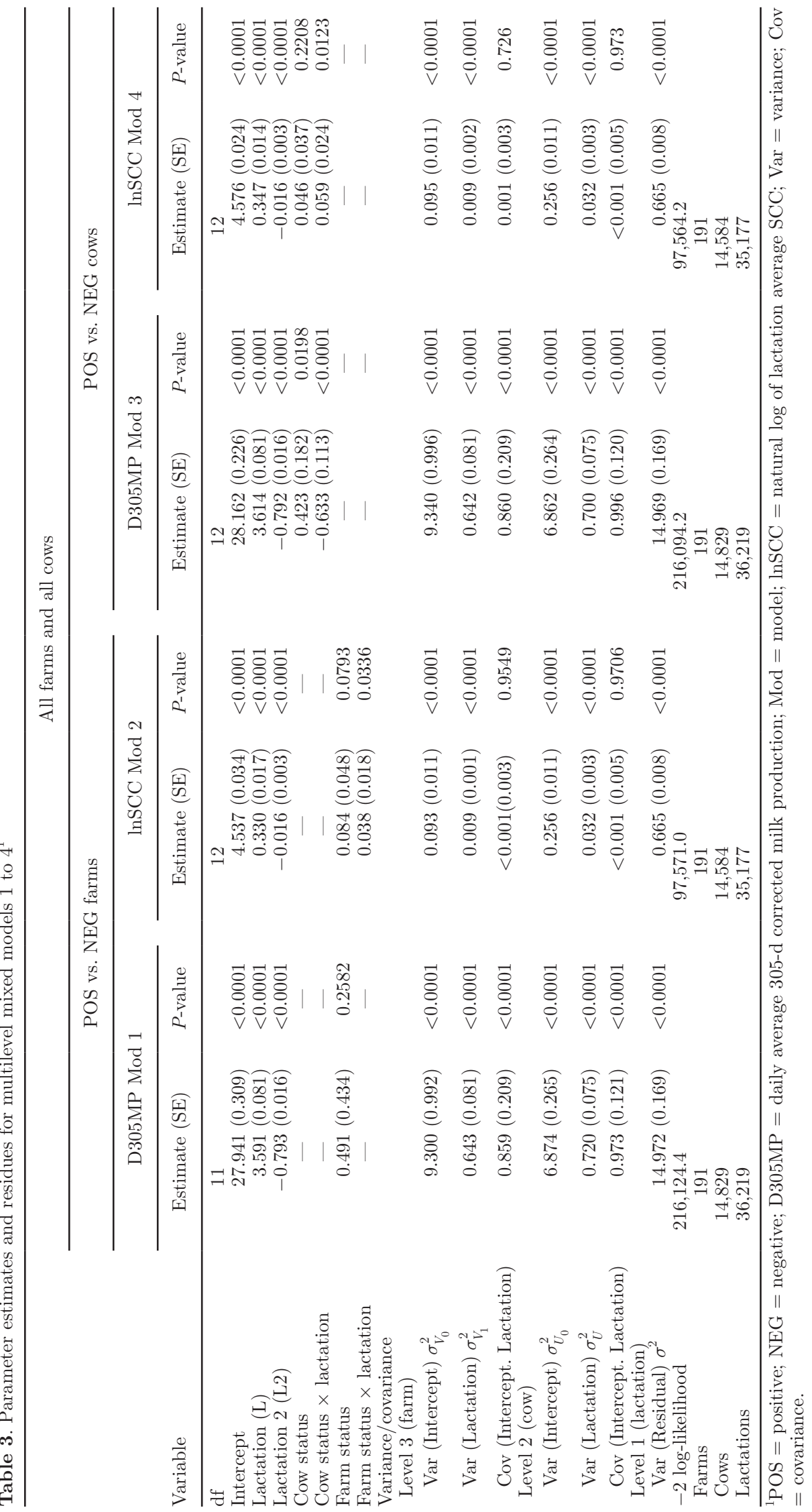



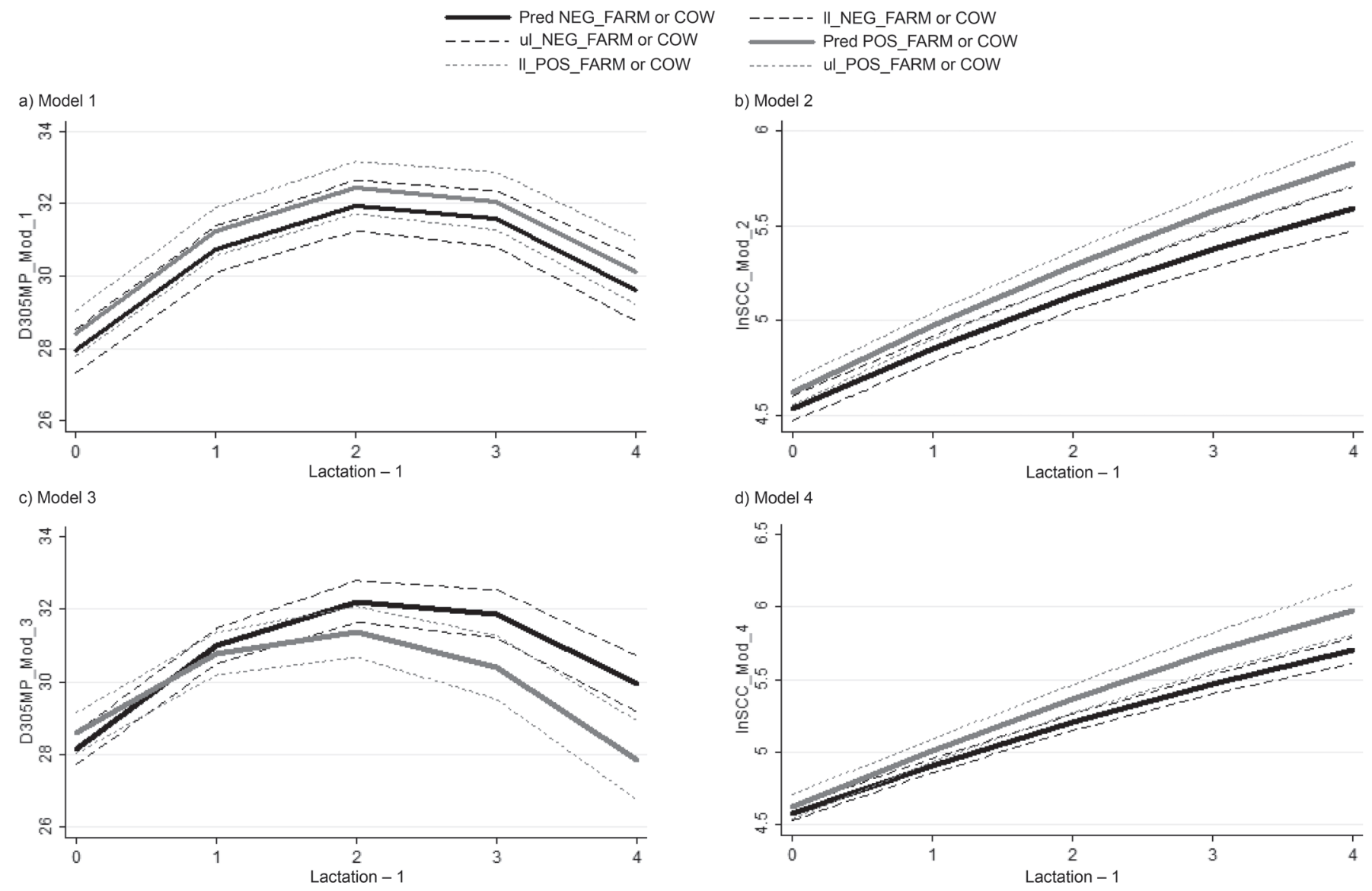

Figure 1. Graphics representing the daily average 305-d corrected milk production (D305MP) expressed in kilograms, and average SCC expressed as its natural $\log (\operatorname{lnSCC})$. $\mathrm{x}$-axis $=$ Lactation -1 ; $\mathrm{y}$-axis $=\mathrm{D} 305 \mathrm{MP}$ (models 1 and 3$)$ or $\operatorname{lnSCC}($ models 2 and 4$)$. Lactation $-1=$ 0 (first lactation) to 4 (fifth lactation). Models 1 and 2 represent D305MP and lnSCC, respectively, in positive (POS) versus negative (NEG) farms. Models 3 and 4 represent D305MP and lnSCC, respectively, in POS versus NEG cows. Mod = model; Pred NEG_FARM = predicted values for negative farms; Pred POS_FARM = predicted values for positive farms; ul_NEG_FARM, ul_POS_FARM, ll_POS_FARM, and ll_NEG_FARM = upper and lower limits of the 95\% CI; Pred NEG_COW = predicted values for negative cows; Pred POS_COW = predicted values for positive cows; ul_NEG_COW, ul_POS_COW, ll_POS_COW, ll_NEG_COW = upper and lower limits of the 95\% CI, respectively.

higher amount of $\operatorname{lnSCC}$ variability is attributable to cow level whereas similar amounts of D305MP variance are retained both by farm and cow levels.

\section{Milk Production}

It is clear that MAP infection reduces lifetime milk production. A strong interaction was observed between CS and L (model 3). It is possible to estimate a cumulative $1,284-\mathrm{kg}$ reduction, on average, per cow over the 5 -lactation period. The results from our models highlight the importance of using lifetime production when assessing MAP infection effects instead of isolated lactations, as this may help to overcome limitations noted by Nielsen et al. (2009).

Models 1 and 2, respectively, showed that POS farms have higher D305MP (although nonsignificant) and sig- nificantly higher lnSCC than NEG farms. These results suggest the existence of differences in the performance of Portuguese POS and NEG farms independent from MAP status. A higher EBV for milk yield has already been reported for MAP-positive herds in Ireland (Hoogendam et al., 2009), but no significant effect of MAP status at animal, lactation, or herd level on milk yield or $\operatorname{lnSCC}$ was found. That might be because only one lactation per cow was evaluated and irrespective of parity number.

Our study also shows that the infected population of cows had, on average, a 0.4 (model 3 ) to $0.6 \mathrm{~kg} / \mathrm{d}$ (model 7, Supplemental Table S1; https://doi.org/10 .3168/jds.2017-13746) higher D305MP during the first lactation, supporting previous suggestions that higher susceptibility to infection could be related to increased production capacity. Another possible explanation for 
the observed by-parity differences (model 3) could be the existence of a positive relation between the speed of infection progression and productive merit.

Smith et al. (2009) also reported that infected animals produced more milk than uninfected ones before they began shedding MAP and also that infected cows had monthly decreases of 0.05 to $1 \mathrm{~kg}$ in daily milk production relative to uninfected animals, with greater reductions in progressive disease categories. In a subsequent study (Smith et al., 2016) in which cows were categorized as high path (at least one high-positive culture) or low path (at least one positive culture or ELISA), it was observed that both low- and high-path animals produced more milk before the first positive test than always-negative animals. Although our models did not include information to differentiate the lactation in which a cow becomes positive during the productive lifetime, the positive interaction between CS and L supports the findings of Smith et al. $(2009,2016)$.

It was also observed (Smith et al., 2016) that, although mean production decreased after a first positive test, some low-path animals recovered productivity, showing that not all animals that test positive for MAP will have long-term production losses. This information should be taken into consideration when assessing the D305MP losses from our models, as the proportion of low- and high-path cows within our data set is unknown.

Farm status showed no significant effect on D305MP in the models; likewise, no significant effect was observed in the interaction between FS and L. However, this does not exclude the importance of FS in D305MP losses due to MAP.

Farmers' awareness is relevant for the success in MAP control. In Portugal, when the issue of farm and cow losses is addressed it seems to be difficult to attract veterinarians' or farmers' interest. This might be explained by results from our models, as more than $80 \%$ of the lactations were below lactation 4 (and only $4.7 \%$ are positive) and the cumulative reduction found in the production of the 3 first lactations was only $-418 \mathrm{~kg}$; thus, the effect of MAP infection on the majority of the farms is hardly perceived as important. Nielsen et al. (2009) also observed that the decline in milk production attributable to MAP occurred over a long period, and may not be realized by the herd manager. Several genes, epistasis (gene-togene interactions), and genome-wide associations have been studied and may explain the heritability for MAP infection in cattle; namely in Spain, where the bovine SLC11A1, NOD2, SP110, TLR2, and TLR4 genes have been described as MAP susceptibility loci in Spanish Holstein-Friesians (Ruiz-Larrañaga et al., 2017). Shook et al. (2012) observed a genetic contribution to MAP susceptibility, with high milk yields genetically associated with a slightly increased susceptibility to MAP; heritability estimates for Johne's disease susceptibility were near $15 \%$. Our study showed that POS heifers produce slightly more milk in first lactations than NEG ones, which suggests that higher-production heifers have a higher risk of infection than the less productive ones. This probably influenced farmers to exert selection pressure toward an increasingly susceptible cow population in recent decades and may continue to do so in the nearby future. Thus, the natural trend for farmers to select for milk production ability may be an important driver for increasing infection prevalence.

\section{SCC}

Positive significant associations between SCC and MAP have been reported in several previous studies (Baptista et al., 2008; McNab et al., 1991; Pritchard et al., 2017). The association between MAP and clinical mastitis (Rossi et al., 2017), subclinical mastitis (Pritchard et al., 2017), and higher culling rates (Smith et al., 2010) has also been previously documented. Our models showed a significant association between $\operatorname{lnSCC}$ and MAP POS CS, which is dependent from lactation number and farm. In model 2 we found that MAP POS farms had higher lnSCC than NEG farms and that lnSCC was significantly influenced by an interaction between L and FS. The higher production levels found in MAP POS farms, the type of facilities, and udder health management could explain this finding, which needs to be further studied. Model 4 shows a clear association between $\operatorname{lnSCC}$ and MAP infection, with an interaction between $\mathrm{CS}$ and $\mathrm{L}$. The model shows that MAP POS cows have higher lnSCC than MAP NEG ones and that the difference in lnSCC between these 2 groups increases with lactations, over the production lifetime of the cows, due to the interaction. This is particularly interesting and could be anticipated after the above-mentioned studies, but it was not clearly seen, as the temporal dependency from successive lactations for the same cow was not addressed in those studies. The association between SCC and MAP was expected, as the immune system from cows affected by MAP should be progressively weakened, resulting in higher susceptibility to udder infection (Pritchard et al., 2017). Recently, Rossi et al. (2017) reported that cows with progressive and nonprogressive infection had higher average SCC than MAP-negative animals, and that latent animals had higher average SCC than MAP-negative animals. Pritchard et al. (2017), in a study where cows were classified as low-, medium- and high-risk based on multiple MAP testing, found that the log-transformed lactationaverage SCC from medium- and high-risk cows was 
higher than for low-risk cows, and differences were in almost all cases significant. These studies are in line with our findings.

One limitation of our study was that infection stage or seroconverting pattern of the cows was not accounted for, as the majority of the cows were tested only once. All lactations from cows with a positive test were assumed to be positive, which is a biologically plausible assumption (Smith et al., 2016; Pritchard et al., 2017). Having just 1 test per cow is a limitation of the study, given the existence of several recognized infection patterns (Nielsen et al., 2009; Mitchell et al., 2015), which could not be specifically addressed in our models.

Another limitation was the case definition of POS cow, based on ELISA tests, which often lack sensitivity; thus, low-prevalence herds could have gone undetected and some infected cows could have been erroneously classified as negative. The effect of these limitations of the study would always be the underestimation of the real effects of MAP on D305MP and lnSCC. The test is not $100 \%$ specific; therefore, some false-positive cows could have been erroneously categorized.

In our models, the arithmetic average of the SCC within the lactation was log-transformed. The dilution effect was not accounted for. This factor has been found to interfere with the inference from production losses by Green et al. (2006), but not by Boland et al. (2013). Græsbøll et al. (2016) found that the dilution factor is of importance to be accounted for when developing predictive models for lactation outcomes. However, our study was not meant to produce such inferences or predictive modeling, but to make the comparison of SCC between 2 groups. It is noteworthy that studies about the dilution factor are based on individual testday measurements and are intended to draw inferences, which was not the case in our study. In line with other authors (Pritchard et al., 2017; Rossi et al., 2017), we did not consider such correction in the models. We considered that the comparability between the 2 groups should not be affected, as the dilution effect would be present in both groups of cows in the same manner. Additionally, in our results, the dilution effect would favor a reduction in $\operatorname{lnSCC}$ of POS first lactations, given their observed higher milk production.

The use of the log-transformation of the weighted arithmetic average of SCC within the lactation deserves further comment, as this average aggregates all the test-day measurements from an entire lactation. High values of $\operatorname{lnSCC}$ can occur after chronic cows or from a mix of chronic and clinical mastitis measurements occurring during 1 lactation of a particular cow. With a measure of variability to complement the mean of $\operatorname{lnSCC}$ a better insight into this variable would be provided, but this could not be calculated from our data set, which is a limitation from our study. However, it is reasonable to expect that the $\operatorname{lnSCC}$ can differentiate cows with chronic or with multiple clinical episodes of mastitis from those experiencing a sporadic episode of mastitis during the lactation.

Selection bias from premature exclusion of MAP POS cows was not likely to occur in our sample because elimination of MAP POS animals was not required by the industry or the veterinary authorities in Portugal. Furthermore, the inclusion criteria for cows was at least 210 DIM; hence, the bias from exclusion should be small.

Strengths of our study were that it was performed using a large data collection spanning a broad temporal scope in a 3-level structure. Several lactations of the same cow were included, accounting for the lifelong effect of MAP infection. Exclusion criteria were applied to prevent the occurrence of small number of observations in any strata, and farm classification was done with more than 2 POS cows and more than 20 animals tested. The ELISA tests and SCC were performed by an ISO 17025-accredited (https://www.iso.org/standard/ 39883.html) laboratory.

\section{CONCLUSIONS}

The proportion of POS farms in our sample was $29.2 \%$. However, the proportion of farms with at least a positive cow was higher, $47.4 \%$. At cow level, the proportion of positives was $4.5 \%$. The POS farms had higher SCC than negative farms. Lactation was the major driver in affecting individual productivity. Positive cows produced, on average, 1,284 kg less (cumulative reduction) across 5 lactations than NEG cows, although the effect is only observable from the second lactation onwards. On their first lactations, POS cows had, on average, higher production than their negative herd mates. Regarding $\operatorname{lnSCC}$, we noted an interaction of CS and FS with lactation, so the magnitude of effect of MAP on lnSCC depends on lactation number. It is important to alert the dairy farming industry that, because of the POS cows' best performance in first lactations, current culling strategies may be selecting for increased MAP infection susceptibility.

\section{ACKNOWLEDGMENTS}

The authors thank SEGALAB SA (Laboratório de Sanidade Animal e Segurança Alimentar, Argivai, Portugal), EABL (Estação de Apoio à Bovinicultura Leiteira, Aveiro, Portugal), SNIRB-IFAP (Sistema Nacional de Identificação e Registo de Bovinos-Instituto de Financiamento da Agricultura e Pescas, Lisbon, Portugal)), and Abigaíl Barbosa, Adelaide Pereira 
(SEGALAB), António Ferreira (EABL), and Sales Henriques (SNIRB) for their contribution to this work.

\section{REFERENCES}

Baptista, F. M., S. S. Nielsen, and N. Toft. 2008. Association between the presence of antibodies to Mycobacterium avium subspecies paratuberculosis and somatic cell count. J. Dairy Sci. 91:109-118. https://doi.org/10.3168/jds.2007-0502.

Boland, F., L. O'Grady, and S. J. More. 2013. Investigating a dilution effect between somatic cell count and milk yield and estimating milk production losses in Irish dairy cattle. J. Dairy Sci. 96:14771484. https://doi.org/10.3168/jds.2012-6025.

Coelho, A. C., M. P. Pinto, A. Matos, M. Matos, and M. A. Pires. (2013). Mycobacterium avium complex in domestic and wild animals. Pages 91-111 in Book Insights from Veterinary Medicine. https://doi.org/10.5772/54323.

Correia-Gomes, C., D. Mendonça, and J. Niza-Ribeiro. 2010. Risk associations to milk ELISA result for paratuberculosis in dairy cows in northern Portugal using a multilevel regression model. Rev. Med. Vet. (Toulouse) 161:295-301..

Davis, W. C. 2015. On deaf ears, Mycobacterium avium paratuberculosis in pathogenesis Crohn's and other diseases. World J. Gastroenterol. 21:13411-13417. https://doi.org/10.3748/wjg.v21.i48.13411.

Donat, K., A. Soschinka, G. Erhardt, and H. R. Brandt. 2014. Paratuberculosis: decrease in milk production of German Holstein dairy cows shedding Mycobacterium avium ssp. paratuberculosis depends on within-herd prevalence. Animal 8:852-858. https://doi.org/10 $.1017 /$ S1751731114000305.

Eisenberg, S. W. F., E. Veldman, V. P. M. G. Rutten, and A. P. Koets. 2015. A longitudinal study of factors influencing the result of a Mycobacterium avium ssp. paratuberculosis antibody ELISA in milk of dairy cows. J. Dairy Sci. 98:2345-2355. https://doi.org/10 .3168/jds.2014-8380.

Græsbøll, K., C. Kirkeby, S. S. Nielsen, T. Halasa, N. Toft, and L. E. Christiansen. 2016. Models to estimate lactation curves of milk yield and somatic cell count in dairy cows at the herd level for the use in simulations and predictive models. Front. Vet. Sci. 3:115. https://doi.org/10.3389/fvets.2016.00115.

Green, L. E., Y. H. Schukken, and M. J. Green. 2006. On distinguishing cause and consequence: Do high somatic cell counts lead to lower milk yield or does high milk yield lead to lower somatic cell count? Prev. Vet. Med. 76:74-89. https://doi.org/10.1016/j .prevetmed.2006.04.012.

Hoogendam, K., E. Richardson, and J. Mee. 2009. Paratuberculosis sero-status and milk production, SCC and calving interval in Irish dairy herds. Ir. Vet. J. 62(Suppl. 4):265-271. https://doi.org/10 .1186/2046-0481-62-4-265.

Laurin, E. L., M. Chaffer, J. T. McClure, S. L. B. McKenna, and G. P. Keefe. 2015. The association of detection method, season, and lactation stage on identification of fecal shedding in Mycobacterium avium ssp. paratuberculosis infectious dairy cows. J. Dairy Sci. 98:211-220. https://doi.org/10.3168/jds.2014-8406.

Laurin, E. L., J. Sanchez, M. Chaffer, S. L. B. McKenna, and G. P. Keefe. 2017. Assessment of the relative sensitivity of milk ELISA for detection of Mycobacterium avium subspecies paratuberculosis infectious dairy cows. J. Dairy Sci. 100:598-607. https://doi.org/ 10.3168/jds.2016-11194.

Mato, I., N. Pesqueira, C. Factor, M. L. Sanjuán, E. Yus, R. Fouz, I. Arnaiz, F. Caminob, and F. J. Diéguez. 2015. Effect of Mycobacterium avium ssp. paratuberculosis infection status on culling and calving difficulty in dairy cattle. Livest. Sci. 177:151-158. https:// doi.org/10.1016/j.livsci.2015.04.015.

McAloon, C. G., P. Whyte, S. J. More, M. J. Green, L. O'Grady, A. Garcia, and M. L. Doherty. 2016. The effect of paratuberculosis on milk yield-A systematic review and meta-analysis. J. Dairy Sci. 99:1449-1460. https://doi.org/10.3168/jds.2015-10156.

McNab, W. B., A. H. Meek, S. W. Martin, and J. R. Duncan. 1991. Associations between dairy production indices and lipoarabino- mannan enzyme-immunoassay results for paratuberculosis. Can. J. Vet. Res. 55:356-361.

Mitchell, R. M., R. H. Whitlock, Y. T. Gröhn, and Y. H. Schukken. 2015. Back to the real world: Connecting models with data. Prev. Vet. Med. 118:215-225. https://doi.org/10.1016/j.prevetmed.2014 .12 .009 .

More, S., A. Bøtner, A. Butterworth, P. Calistri, K. Depner, S. Edwards, B. Garin-Bastuji, M. Good, C. Gortázar Schmidt, V Michel, M. A. Miranda, S. S. Nielsen, M. Raj, L. Sihvonen, H Spoolder, J. A. Stegeman, H.-H. Thulke, A. Velarde, P. Willeberg, C. Winckler, F. Baldinelli, A. Broglia, G. Zancanaro, B. BeltránBeck, L. Kohnle, J. Morgado, and D. Bicout. 2017. Assessment of listing and categorisation of animal diseases within the framework of the Animal Health Law (Regulation (EU) No 2016/429): paratuberculosis. EFSA J. 15. https://doi.org/10.2903/j.efsa.2017 .4960 .

Nielsen, S. S., M. A. Krogh, and C. Enevoldsen. 2009. Time to the occurrence of a decline in milk production in cows with various paratuberculosis antibody profiles. J. Dairy Sci. 92:149-155. https:// doi.org/10.3168/jds.2008-1488.

Nielsen, S. S., and N. Toft. 2009. A review of prevalences of paratuberculosis in farmed animals in Europe. Prev. Vet. Med. 88:1-14. https://doi.org/10.1016/j.prevetmed.2008.07.003.

Pritchard, T. C., M. P. Coffey, K. S. Bond, M. R. Hutchings, and E. Wall. 2017. Phenotypic effects of subclinical paratuberculosis (Johne's disease) in dairy cattle. J. Dairy Sci. 100:679-690. https://doi.org/10.3168/jds.2016-11323.

Rossi, G., Y. T. Grohn, Y. H. Schukken, and R. L. Smith. 2017. The effect of Mycobacterium avium subspecies paratuberculosis infection on clinical mastitis occurrence in dairy cows. J. Dairy Sci. 100:7446-7454. https://doi.org/10.3168/jds.2017-12721.

Ruiz-Larrañaga, O., P. Vázquez, M. Iriondo, C. Manzano, M. Aguirre, J. M. Garrido, J. Ramon, and A. Estonba. 2017. Evidence for gene-gene epistatic interactions between susceptibility genes for Mycobacterium avium ssp. paratuberculosis infection in cattle. Livest. Sci. 195:63-66. https://doi.org/10.1016/j.livsci.2016.11.012

Sechi, L. A., and C. T. Dow. 2015. Mycobacterium avium ssp. paratuberculosis Zoonosis - The hundred year war-Beyond Crohn's Disease. Front. Immunol. 6:96-8. https://doi.org/10.3389/fimmu .2015 .00096

Shook, G. E., M. Chaffer, X. L. Wu, and E. Ezra. 2012. Genetic parameters for paratuberculosis infection and effect of infection on production traits in Israeli Holsteins. Anim. Genet. 43(SUPPL. 1):56-64. https://doi.org/10.1111/j.1365-2052.2012.02349.x.

Singh, S. V., J. T. Kuenstner, W. C. Davis, P. Agarwal, N. Kumar, D. Singh, S. Gupta, K. K. Chaubey, A. Kumar, J. Misri, S. Jayaraman, J. S. Sohal, and K. Dhama. 2016. Concurrent resolution of chronic diarrhea likely due to Crohn's disease and infection with Mycobacterium avium paratuberculosis. Front. Med. 3:49. https:// doi.org/10.3389/fmed.2016.00049.

Smith, R. L., Y. T. Grohn, A. K. Pradhan, R. H. Whitlock, J. S. Van Kessel, J. M. Smith, D. R. Wolfgang, and Y. H. Schukken. 2009. A longitudinal study on the impact of Johne's disease status on milk production in individual cows. J. Dairy Sci. 92:2653-2661. https:// doi.org/10.3168/jds.2008-1832.

Smith, R. L., Y. T. Gröhn, A. K. Pradhan, R. H. Whitlock, J. S. Van Kessel, J. M. Smith, D. R. Wolfgang, and Y. H. Schukken. 2016. The effects of progressing and nonprogressing Mycobacterium avium ssp. paratuberculosis infection on milk production in dairy cows. J. Dairy Sci. 99:1383-1390. https://doi.org/10.3168/ jds.2015-9822.

Smith, R. L., R. L. Strawderman, Y. H. Schukken, S. J. Wells, K. Pradhan, L. Espejo, R. H. Whitlock, J. S. Van Kessel, J. M. Smith, D. R. Wolfgang, and Y. T. Gröhn. 2010. Effect of Johne's disease status on reproduction and culling in dairy cattle. J. Dairy Sci. 93:3513-3524. https://doi.org/10.3168/jds.2009-2742.

Stabel, J. R., L. Bradner, S. Robbe-Austerman, and D. C. Beitz. 2014. Clinical disease and stage of lactation influence shedding of $\mathrm{Myco-}$ bacterium avium subspecies paratuberculosis into milk and colos- 
trum of naturally infected dairy cows. J. Dairy Sci. 97:6296-6304. https://doi.org/10.3168/jds.2014-8204.

Timms, V. J., M. M. Gehringer, H. M. Mitchell, G. Daskalopoulos, and B. A. Neilan. 2011. How accurately can we detect Mycobacterium avium ssp. paratuberculosis infection? J. Microbiol. Methods 85:1-8. https://doi.org/10.1016/j.mimet.2011.01.026.

Vasconcelos, J., A. Martins, M. F. Petim-Batista, J. Colaço, R. W. Blake, and J. Carvalheira. 2004. Prediction of daily and lactation yields of milk, fat, and protein using an autoregressive repeatability test day model. J. Dairy Sci. 87:2591-2598. https://doi.org/10 .3168/jds.S0022-0302(04)73384-6.

Waddell, L. A., A. Rajić, K. D. C. Stärk, and S. A. Mcewen. 2015. The zoonotic potential of Mycobacterium avium ssp. paratuberculosis: A systematic review and meta-analyses of the evidence. Epidemiol. Infect. 143:3135-3157. https://doi.org/10.1017/ S095026881500076X

\section{Appendix}

The model structures and corresponding equations are shown below.

\section{Level 1: Measurement Occasion}

Level 1, representing the measurement occasion, is given by

$$
y_{i j k}=\beta_{0 j k}+\beta_{1 j k} L_{i j k}+\beta_{2 j k} L_{i j k}^{2}+\varepsilon_{i j k},
$$

where $y_{i j k}$ represents either milk production or SCC:

$$
\begin{gathered}
y_{i j k}=\mathrm{D} 305 \mathrm{MP}_{i j k} \quad \text { Milk production } \\
y_{i j k}=\operatorname{lnSCC}_{i j k} \quad \ln \mathrm{SCC}
\end{gathered}
$$

where $i$ is the measurement occasion, $j$ represents the cow, and $k$ corresponds to the farm $\left(i=0,1, \ldots, L_{i}=\right.$ Lactation $\left._{i j k}-1 ; j=1,2, \ldots, C_{j k} ; k=1,2, \ldots, F_{k}\right), \beta$ terms are regression coefficients at Level 1 , and $\varepsilon_{i j k}$ is the residual error. This equation is common to both models $\mathrm{A}$ and $\mathrm{B}$.

\section{A: Model Cow Status}

Level 2-Cow

$$
\begin{aligned}
& \beta_{0 j k}=\delta_{00 k}+\delta_{01 k} C S_{j k}+U_{0 j k} \\
& \beta_{1 j k}=\delta_{10 k}+\delta_{11 k} C S_{j k}+U_{1 j k} \\
& \beta_{2 j k}=\delta_{20 k}
\end{aligned}
$$

where $\delta$ terms are regression coefficients at Level 2.

Level 3-Farm

$$
\begin{aligned}
& \delta_{00 k}=\gamma_{000}+V_{00 k} \\
& \delta_{01 k}=\gamma_{010} \\
& \delta_{10 k}=\gamma_{100}+V_{10 k} \\
& \delta_{11 k}=\gamma_{110} \\
& \delta_{20 k}=\gamma_{200}
\end{aligned}
$$

where $\gamma$ terms are global fixed regression coefficients at Level 3. 


\section{B: Model Farm Status}

Level 2-Cow

$$
\begin{aligned}
& \beta_{0 j k}=\delta_{00 k}+U_{0 j k} \\
& \beta_{1 j k}=\delta_{10 k}+U_{1 j k} \\
& \beta_{2 j k}=\delta_{20 k}
\end{aligned}
$$

where $\delta$ terms are regression coefficients at Level 2 .

Level 3-Farm

$$
\begin{aligned}
& \delta_{00 k}=\gamma_{000}+\gamma_{010} F S_{k}+V_{00 k} \\
& \delta_{10 k}=\gamma_{100}+\gamma_{110} F S_{k}+V_{11 k} \\
& \delta_{20 k}=\gamma_{200}
\end{aligned}
$$

where $\gamma$ terms are global fixed regression coefficients at Level 3 .

Global Model A:

$$
y_{i j k}=\gamma_{000}+\gamma_{010} C S_{j k}+\gamma_{100} L_{i j k}+\gamma_{110} C S_{j k} L_{i j k}+\gamma_{200} L_{i j k}^{2}+\underbrace{U_{0 j k}+V_{00 k}+\left(V_{10 k}+U_{1 j k}\right) L_{i j k}}_{\text {Random effects }}+\underbrace{\varepsilon_{i j k}}_{\text {Error }},
$$

Global Model B:

$$
y_{i j k}=\gamma_{000}+\gamma_{010} F S_{k}+\gamma_{100} L_{i j k}+\gamma_{110} F S_{k} L_{i j k}+\gamma_{200} L_{i j k}^{2}+\underbrace{U_{0 j k}+V_{00 k}+\left(U_{1 j k}+V_{11 k}\right) L_{i j k}}_{\text {Random effects }}+\underbrace{\varepsilon_{i j k}}_{\text {Error }},
$$

where $L_{i}=$ Lactation $_{i}-1, C S=$ cow status, and $F S=$ farm status; $\varepsilon_{i j k} \sim N\left(0, \sigma^{2}\right)$ is residual error at Level 1; $U_{0 j k} \sim N\left(0, \sigma_{U_{0}}^{2}\right)$ is random residual error term at Level 2 intercept; $U_{1 j k} \sim N\left(0, \sigma_{U_{1}}^{2}\right)$ is random residual error term at Level 2 slope; $V_{00 k} \sim N\left(0, \sigma_{V_{0}}^{2}\right)$ is random residual error term at Level 3 intercept; and $V_{10 k} \sim N\left(0, \sigma_{V_{1}}^{2}\right)$ is random residual error term at Level 3 slope. 